\title{
ARTAUD E O MEIO PARA OS DEVIRES-LOUCO
}

\section{ARTAUD AND THE MIDDLE FOR THE MAD BECOMINGS}

Diego Lock Farina (UFRGS)

diegolockfarina@hotmail.com

\begin{abstract}
RESUMO: $O$ presente artigo analisa os agenciamentos entre a obra de Artaud e o desdobramento de alguns de seus conceitos operado por Deleuze no campo do pensamento imanente. Partindo de Pour en finir avec le jugement de dieu e da poética da crueldade, Artaud erige o "Corpo sem órgãos", que declara combate ao organismo antropocêntrico, em nome da liberdade pré-individual, do fim do juízo, e pela demanda de uma história do impossível na linguagem. Fora $e$ devir, gagueira $e$ esquizofrenia enquanto estilo, encontram em Deleuze singulares problematizações ético-politicas através da literatura como empreendimento de saúde. Nesse intuito, tensionamos sobretudo as leituras de Grossman e Blanchot acerca do silêncio e do sofrimento artauniano com o pensamento sem imagem deleuziano, no sentido de explorarmos as reais metamorfoses que acontecem em meio a esse processo artístico antimimético, não-teleológico, não-identitário e que, enfim, provoca os limites do ontológico, promovendo a multiplicidade no plano da criação.
\end{abstract}

PALAVRAS-CHAVE: devir; Artaud; corpo-sem-órgãos; antimimético.

ABSTRACT: This paper analyses the agencements between Artaud's work and the unfolding of some of his concepts operated by Deleuze in the field of immanent thought. Starting from Pour en finir avec le jugement de dieu and the poetics of cruelty, Artaud develops the "Body without organs", which declares combat against the anthropocentric organism, in the name of pre-individual freedom, the end of judgment, and the demand for a history of the impossible in language. Outside and becoming, stuttering and schizophrenia as a style, find in Deleuze singular ethical-political problematizations through literature as a health enterprise. With this aim, we contrasted above all Grossman and Blanchot's readings about Artaunian's silence and suffering with Deleuzian thought without image, in order to explore the real metamorphoses that take place in the midst of this anti-mimetic, non-teleological, non-identitarian artistic process, which questions the limits of the ontological, promoting multiplicity in the plan of creation.

KEYWORDS: becoming; Artaud; body without organs; anti-mimetic. 


\section{Introdução}

Para dar voltas no parafuso do fim do juízo. Para dar múltiplos fins fora das finalidades. Fim ao julgamento de deus, à soberania da representação nas artes, às metáforas que despertam disso e, finalmente, à metáfora. Discípulo do amoralismo racionalista de Espinoza - inusitado ateísta, escatológico -, Antonin Artaud (1896-1948) precisou singularmente padecer do juízo. Entendamos por juízo, numa espiral das legislações exteriores à sanidade mental, toda a implicação nos corpos/corpus de formas morais/teológicas que demarcam limites, códigos, sistemas. O juízo intui o território, que intui, consequentemente, a privação. De Van Gogh a Artaud, entretanto, o signo da crueldade se exalta frente à sociedade que suicida. "Uso a palavra crueldade no sentido de apetite de vida, de rigor cósmico e de necessidade implacável, no sentido gnóstico de turbilhão de vida que devora as trevas" (ARTAUD, 1999, p. 119). A esquizofrenia se alastra para fora da psiquiatria e a proposta artauniana de uma poética da crueldade se apresenta como o inverso do que Nietzsche, na Genealogia da moral, destaca como a condição do juízo: "a 'consciência de ter uma dívida para com a divindade', a aventura da dívida à medida que ela mesma se torna infinita, portanto, impagável” (DELEUZE, 2011, p. 162). A concepção do juízo que nos liga à dívida faz sobreviver o devedor, ou seja, é devendo que se ganha (as migalhas) a concessão de permanecer. Deleuze e Guattari (2018, p. 222) ligam igualmente a dívida - vista como uma superestrutura consciente desde Lévi-Strauss - à representação e à memória: "la dette est l'unité d'alliance, et l'alliance est la représentation même. C'est l'alliance qui code les flux du désir et qui, par la dette, fait à l'homme une mémoire des paroles"'. A dívida, em parcelas, sob seu aspecto psíquico ou transcendente, supostamente se paga com a Vida. E são obras que acontecem, por extensão, na vida, na multiplicidade e fora da posição de um sujeito, como é o caso inevitável de Artaud, que dão provas de que o juízo comporta a demanda por seu próprio fim, sob a qualidade, podemos dizer, de um autoexpurgo.

O que se distingue do juízo?, dessa aparição do uno, é a dissonante pergunta que Artaud leva adiante. Notemos que uma dimensão livresca do juízo materializa a doutrina do tribunal na cultura e nas práticas que autenticam tal instituição. Ou seja, o que está fora do livro, deve ser punido. Ou melhor, deve ser trazido/transportado para dentro, com a condição de se adaptar ao formalismo narcísico da normopatia e à provação. Ora, os escritos de Artaud invertem o signo insistente das leis ao se oporem ao projeto, tantas vezes requisitado na história da

\footnotetext{
1 “a dívida é a unidade da aliança, e a aliança é a própria representação. É a aliança que codifica os fluxos do desejo e que, através da dívida, dá ao homem uma memória das palavras”. Tradução do autor.
} 
literatura, do livro total, do Livro, de Mallarmé a Jabès, entre tantos outros; podemos dizer que seus escritos, aliás, voltam-se contra toda escrita, sobretudo contra a escrita dos mestres e das modas, e, a respeito dos signos, é preciso dizer: o empenho de Artaud sempre foi o de devolver ao signo sua ligação vivente com o afecto, toda sua liberdade ofuscada, surrupiada, inclusive pelo modelo de Saussure, que enjaula significado e significante sob uma inseparável configuração. O signo, enquanto posição de desejo, deve voltar a se deslocar livremente entre os mais diferentes planos (dança, música, escrita, teatro...). Pour en finir avec le jugement de dieu, finalizada em 1948, é por isso uma obra que se destaca a partir de sua manifestação esparsa, em princípio, fora da letra escrita, onde o signo está rachado (trata-se de uma rádio emissão performada à base de improvisos, acompanhada por elementos sonoros não-verbais, gritos, barulhos de objetos, tambores atravessados etc.). O que significa o acontecimento desse derradeiro decreto ao próprio juízo, ao livro e ao juízo do livro, do corpo ao corpus?

$\mathrm{Na}$ alternância do fundante símbolo da cruz, e de todas as suas patéticas significâncias, a escrita rompe seu limite espacial, acelerando-se rumo às corporeidades, das com órgãos às sem. Não à toa, são inúmeras as referências de Artaud a uma ação literária que sai do papel para se dirigir ao espaço de fora do palco convencional, do morfológico e do visível. Ao que concerne o novo espaço teatral, por exemplo, Artaud defende que não haja mais a separação "scène-salle", o que, assim, vem a facilitar a participação do espectador que devém de uma “certaine manière lui-même acteur ; l'identification est également facilitée par l'abolition de la distance, mais Artaud insiste bien sur le fait qu'il ne s'agit pas d'identification à la personne mais plutôt à l'événement en train de s'accomplir."2 (ALBERTI, 1999, p. 249), sendo o happening e a arte-performance, dos anos sessenta em diante, prolongamentos nítidos de tais experiências. A escrita, não distante disso, agora é de sangue, berros, fezes, esperma, fluidos e matéria vital que escorre; ela forma e fornece "imágenes larvales", pois, diz-nos Artaud (2014, p. 83), "soy un hombre por mis manos y por mis pies, mi vientre, mi corazón de carne, mi estómago cuyos nudos me acercan a la putrefacción de la vida"3. Em contraposição à poesia dos poetas, afirma Évelyne Grossman (2003), Artaud investe sua raiva intestinal em forma de poesia digestiva. As malignas encarnações dos verbos fazem com que cada autor devore a própria substância, para dela se nutrir, deglutindo seu eu sob repugnantes operações incestuosas

\footnotetext{
2 “de uma certa maneira ele mesmo ator; a identificação é igualmente facilitada pela abolição da distância, porém Artaud insiste bastante sobre o fato de que isso não se trata de uma identificação a alguém, mas sim ao acontecimento em seu processo de realização". Tradução do autor.

3 “sou um homem pelas minhas mãos e pelos meus pés, meu ventre, meu coração de carne, meu estômago cujos nós me aproximam da putrefação da vida”. Tradução do autor.
} 
de prazer consigo mesmo. No lugar da poesia auto-antropofágica, da poesia objeto decorativo ou de qualquer produção que se qualifique como literária, limitada à dinastia verbal, Artaud desdobra sua “poésie-force, incantation, rythme, 'la poésie dans l'espace' (ce qu'il nomme théâtre), le mouvement des syllabes proférées, expectorées - les corps animés des mots"4 (GROSSMAN, 2003, p. 8). Contra a poesia individual, engendra-se uma poesia como rito coletivo, teatral e profano, como ato político, no qual a limpeza de todo resquício religioso e moral se torna a base de um processo radicalmente iconoclasta. $\mathrm{O}$ esquizofrênico, portanto, passeia na poesia. Arranca-lhe as flores, os símbolos de adoração e submissão, a aura e a dívida. Livra-nos da coroa de espinhos que herdamos por representação. É quando a coroa de espinhos é posta em Jesus, então agarrado à cruz, que, não por coincidência, Pilatos profere: eis o homem.

Em Artaud, que se autodenomina como o louco, o momo, o homem demente, fica claro o objetivo de reenviar a loucura de volta ao mundo. Emiti-la e dissipá-la. O fundo das emissões radiofônicas tem a ver com um singular intuito de partilha, de viver-com, mas também de cruel devolução enquanto gesto político, catártico, formando um paradoxo entre conjuro de si e compartilhamento com outrem que só poderá se manifestar através de um pensamento, de uma razão, sem imagem. O receptor passivo é sensivelmente deslocado da posição de voyeur para o papel de coautor de um rito que investiga a criação impossível. A busca da fecalidade - da fecalidade perdida, a contrastar com Proust - encontra seu autêntico devir à medida que emanações afectivas, sensíveis e anárquicas, invadem o campo dos sentidos, dos princípios e das aparências, produzindo uma atmosfera de sugestão hipnótica que cartografa tal busca e captura o espectador como num rito de peyote para os Tarahumaras, povo com o qual Artaud conviveu durante sua viagem ao México em 1936-37:

\begin{abstract}
D'un côté donc, la culture occidentale (Colomb, l'impéralisme américain, celui de ces colonisateurs qui occupent, dit Artaud, "toute la surface de l'ancien continent indien)", de l'autre la culture indienne, celle de la Terre rouge et des rites sacrés précolombiens. D'un côté encore, l'usinage des corps, la fécondation artificielle, "les ignobles ersatz synthétiques", la sexualité marchande, le corps anatomique, la création machinique, Dieu, ses missionnaires, ses croisés et la guerre contre l'Homme. De l'autre, le peuple indien exproprié (sans terre ni corps "propre"), étranger à la conscience individuelle occidentale, peuple fou, sans identité ni moi personnel, peuple du rite, de la danse et du Théâtre de la Cruauté, celui de la revendication de l'Infini de "l'Homme incréé". Tel est donc le mythe qu'Artaud va mettre en scène une fois plus, en 1948, à l'aube de la guerre froide, dans les studios de la Radiodiffusion ${ }^{5}$ (GROSSMAN, 2003, p. 11).
\end{abstract}

\footnotetext{
4 “poesia-força, encantamento, ritmo, 'a poesia no espaço' (o que chama por teatro), o movimento das sílabas proferidas, expectoradas - os corpos animados das palavras". Tradução do autor.

5 "De um lado, portanto, a cultura ocidental (Colombo, o imperialismo americano, o tipo desses colonizadores que ocupam, diz Artaud, 'toda a superfície do antigo continente indígena'), de outro, a cultura indígena, aquela da Terra vermelha e dos ritos sagrados pré-colombianos. De um outro lado ainda, a usinagem dos corpos, a fecundação artificial, 'os ignóbeis ersatz sintéticos', a sexualidade comercializada, o corpo anatômico, a criação
} 
De acordo com a cultura ocidental do juízo, platonicamente inflamada, é essencial a garantia de existências recortadas em lotes concedidos idealmente por deus aos homens em dívida. Se ter um lote significará ser um homem - ter o lastro da coroa de espinhos -, o que sucederá com quem não o tiver? Explorando a relação entre Espinoza e Artaud, Deleuze (2011) nos dirá que a doutrina teológica do juízo derrubou e substituiu o sistema físico e cruel dos afectos. A lei “de la nature n'est jamais une règle de devoirs, mais la norme d'un pouvoir, l'unité du droit, du pouvoir et de son effectuation. À cet égard, on ne fera nulle différence entre le sage et l'insensé, le raisonnable et le dément, le fort et le faible"6 (DELEUZE, 2018, p. 237). Através dos estados mais atípicos de embriaguez - desses sonos sem sonhos tão vivenciados por um Artaud que se afasta gradualmente do surrealismo de Breton, a citar também a insônia para Blanchot, o relâmpago para Lawrence ou a água pura em Henry James - é que se busca o antídoto para a idealização/romantização do sonho e para o juízo. Se o juízo implica a organização dos corpos, o controle pelo organismo sincronizado, percebamos como os órgãos são, simultaneamente, os juízes e os julgados. Deus nos roubou o que Artaud nomeia como o Corpo sem órgãos (Cso) para introduzir o corpo organizado por onde o seu juízo se exerce. Porém o organismo não será somente onde o juízo divino se revela, ele será o espaço formal e circular em que deus dita a lembrança da dívida. Por outro lado, a ideia sem modelo do Cso surge para deflagar a necessidade de resgatarmos esse corpo pré-individual, de inscrição intensiva e afectiva. Uma poderosa vitalidade inorgânica atravessa a extensão desértica do Cso. Mas a que se refere essa vitalidade não-orgânica? De Artaud a Deleuze e Guattari, deduzimos a consolidação de um projeto poético e epistêmico que prioriza essa intensa vitalidade (elan, para Bergson) que, ao passo que desafia os órgãos e o juízo das organizações, manifesta-se como um maquínico acontecimento de dissenso. O Cso - "la substance immanente au sens le plus spinoziste du mot"7 (DELEUZE; GUATTARI, 2018, p. 394) - traduz os devires de implicação da diferença, ofertando-lhes um campo consistente para que realizem suas atualizações. Artaud chega a chamá-lo simplesmente por palco, tendo em vista que esse palco

\footnotetext{
maquínica, Deus, seus missionários, suas cruzes e a guerra contra o Homem. Do outro, o povo indígena expropriado (sem terra e sem corpo 'próprio'), estrangeiro à consciência individual ocidental, povo louco, sem identidade e sem eu pessoal, povo do rito, da dança e do Teatro da Crueldade, aquele da reinvindicação do Infinito do 'Homem não-criado'. Tal é, portanto, o mito que Artaud colocará em cena uma vez mais, em 1948, nos princípios da guerra fria, nos estúdios da Rádio Difusão Francesa”. Tradução do autor.

6 “da natureza nunca é uma regra de deveres, mas a norma de um poder, a unidade do direito, do poder e da sua efetuação. Desse modo, não haverá nenhuma diferença entre o sábio e o insensato, o razoável e o demente, o forte e o fraco". Tradução do autor.

7 “a substância imanente no sentido mais espinozista da palavra”. Tradução do autor.
} 
nada será senão o Mundo. A vitalidade inorgânica se responsabiliza por dar hospitalidade às relações do corpo concreto com forças imperceptíveis que se apossam ou são apossadas por ele. Instalamo-nos na zona dos devires. Mas também nos indagamos sobre a tarefa dos devires, sob seu aspecto ético. E isso, decerto, conjuga-se com a tarefa que passa a caber a nós, a de criar para si um Cso, o que é, por sua vez, a maneira de escapar ao juízo. Es tan duro dejar de existir, dejar de estar dentro de algo (...) No tengo más que una ocupación: volverme a hacer ${ }^{8}$.

Ao longo do desenvolvimento de seu inventário artístico, Artaud elabora o que agora conhecemos por seu sistema da crueldade, sinônimo de vida apaixonada e convulsiva. Triângulo mágico da máquina desejante olho-mão-voz (voz-audição, grafismo-corpo, olho-dor) a partir de Deleuze e Guattari (2018, p. 228): "théâtre de la cruauté qui implique la triple indépendance de voix articulée, de la main graphique et de l'oeil appréciateur" ${ }^{\text {"9 }}$ O incisivo sistema da crueldade opera a substituição do juízo pelo combate, de um vetor consensual para um vetor de dissenso. Conceberemos, nesse imbricamento semântico, assim como ocorre com as máquinas de guerra, pelo estilo da guerrilha, o combate sendo oportunamente oposto à guerra. A guerra converte a destruição em algo justo, a "arte" da guerra é bela, enquanto o combate anuncia a propagação das mais variadas forças de contra-efetuação; é dizer, o combate, o gesto de com-bater, bater contra, mas também bater em conjunto, por blocos intensivos, gera o meio pelo qual o devir se estende, deixando por onde passa suas marcas em forma de risco. O combate é a condição vital para Artaud, e, de fato, sua arte não é bélica e nem bela. Não seria demais aferir que o combate é, em si e para fora de si, seu verdadeiro processo em arte. E em Artaud o combate inaugural se dirige contra deus, o transcendente falsário, o ladrão primeiro:

\begin{abstract}
Nem Artaud nem Lawrence nem Nietzsche suportam o Oriente e seu ideal de não combate; os lugares mais memoráveis são para eles a Grécia, a Etrúria, o México, lugares em que as coisas advêm ou devêm no curso do combate que lhes compõe as forças. Mas sempre que nos querem fazer renunciar ao combate, é um "nada de vontade" que nos é proposto, uma divinização do sonho, um culto da morte, mesmo sob a forma mais suave, a de Buda ou de Cristo enquanto pessoa (...) O juízo de Deus está a favor da guerra, e de modo algum do combate. Mesmo quando se apodera de outras forças, a força da guerra começa por mutilá-las, por reduzi-las ao estado mais baixo. Na guerra, a vontade de potência significa apenas que a vontade quer a potência como um máximo de poder ou de dominação (DELEUZE, 2011, p. 171).
\end{abstract}

O combate se assimila à resistência, vitalista, política, ética - a questão própria da ética, desde Espinoza, mantém-se: como nos tornamos seres ativos?, "la puissance d'agir est la seule

\footnotetext{
8 “É tão duro deixar de existir, deixar de estar dentro de algo (...) Não tenho mais que uma ocupação: voltar a fazerme”. Tradução do autor. Texto de Le Pèse-Nerfs, Artaud (2014, p. 65).

9 "teatro da crueldade que implica a tripla independência da voz articulada, da mão gráfica e do olho apreciador". Tradução do autor.
} 
forme réelle, positive et affirmative d'un pouvoir d'être affecté"10 (DELEUZE, 2018, p. 204) ; sem órgãos, o combate se incorpora ativamente às maneiras para resistir, ao passo em que a guerra traz a rubrica da doença do mundo, do negativo ou do ressentimento, do potencial apagamento massivo. Estar fora do juízo, da lei, transforma-se em estar fora do controle das faculdades mentais, loucura, demência ou infantilismo, termos todos aplicados, em diferentes contextos, a Artaud. A imaturidade, contudo, invoca um problema de foco: não será desde sempre o recém-nascido a figura típica do combate para sobreviver? A possibilidade das relações afectivas, atléticas, impessoais, inovadoras e vitais partem desse combate e a vontade de potência acaba por se mostrar presente mais em um frágil-bebê-resistente no que no arquétipo do homem de guerra. $\mathrm{O}$ que seria se mostrar infantil nesse viés? Com efeito, o pequeno - o menor - é a sede irredutível das forças. Sede, no sentido de ter sede, estar sedento, de cruelmente necessitar nutrir-se, mas também sede no sentido de um espaço, ambiente, de um lugar que sedia, uma sede de resistência. Ambiguidade oportuna, certamente, sobretudo se valorarmos a importância do espaço na concepção poética de Artaud; espaço e expressão (expressão $^{11}$ também nos sentidos correlativos de Espinoza, "explicare et involvere" (DELEUZE, 2018, p. 11), que é aquilo que se difere da revelação), são os dois termos que qualificam seu esforço para com a arte. Artaud lidava frequentemente com as tentativas de o depreciarem por meio da acusação de infantilismo e, ao modo da transvaloração dos valores do senso comum, usava-se da situação a seu proveito, preenchendo seus fazeres poéticos com linhas infernais de miniaturização, de liliputização. Artautaud, o garotinho que faz caca, que anarquiza e brinca com o próprio totô, extraindo igualmente dele instrumentos excrementais aos seus combates e para a constatação da sua singularidade menor.

Dar fim ao juízo, contudo, não significa se isentar da possibilidade de decisão. A crucial decisão filosófica, que joga pelo nome do ser, é o que nos arrasta ao combate; é produto daquilo que jorra vitalmente de um turbilhão de forças invariavelmente contrárias ao julgamento de deus e de tudo que, de tempos em tempos, sucede tal símbolo, preenche seu signo, enfim, suplanta a posição de poder que tiraniza o Mundo. Através do pensamento esquizo de Artaud,

\footnotetext{
10 "a potência de agir é a única forma real, positiva e afirmativa de um poder de ser afetado". Tradução do autor.

${ }^{11}$ Cabe-nos relacionar a ideia de expressão de Espinoza com o empreendimento expressivo-violento de Artaud. Para o Espinoza de Deleuze (2018, p. 159), "l'expression comprend tous ces aspects : complication, explication, inhérence, implication. Ces aspects de l'expression son aussi les catégories de l'immanence; l'immanence se révèle expressive, l'expression imanente, dans un système de relations logiques où les deux notions son corrélatives. Dans ce point de vue, l'idée d'expression rend compte de la véritable activité du participé, et de la possibilite de la participation. C'est dans l'idée d'expression que le nouveau principe d'immanence s'affirme'. Lembremos que essa possibilidade de participação (antinatural, a serviço dos devires) não se dá fora do âmbito da expressão de uma cruel violência, que pode ser vista como uma forma de radiação, vertigem filosófica, golpe irrepresentacional.
} 
Deleuze assinala cinco transformações que opõem a existência decisiva (que é também crítica) - que combate pelo próprio nome e corpo, é dizer, pelo próprio texto - à doutrina do juízo, que ao invés de decidir, aceita que algo maior decida por si. Dirá Blanchot $(2015$, p. 132) que o próprio do escritor "es reservar lo indeciso en la decisión, preservar el ilimitado cerca del limite y no decir nada que no deje intacto todo el espacio de la palabra o la posibilidad de decirlo todo. Y, al mismo tiempo, es preciso decir una sola cosa y no decir más que esta" ${ }^{12}$. O juízo impede a chegada dos novos modos de existência e o tensionamento de Artaud com o juízo de deus promove cinco combates definitivos, conforme frisa Deleuze (2011): 1) da crueldade (inclusive contra si mesmo) contra o suplício infinito (a dívida); 2) do sono insone ou da embriaguez diferencial contra o sonho (mistificador, representativo de Freud em diante, o inconsciente como teatro burguês criticado n'O anti-Édipo); 3) da vitalidade (sobretudo a inorgânica a partir do Cso) contra a organização/organismo (a poesia dos poetas, a síndrome do parnaso); 4) da vontade de potência (ou do agenciamento maquínico de desejo) contra um querer-dominar (estratificação, reterritorialização) e 5) do próprio acontecimento do combate contra a guerra. Um segredo percorre o plano de imanência que liga Artaud e Deleuze: é preciso fazer existir, não julgar. O expressionismo filosófico de Espinoza aparece como sede para esse encontro, pois é Espinoza quem mostra que o problema da existência é um problema de amor e ódio, e não de juízo. O problema, pré-individual, anterior às imagens da razão, colocado em termos de forças, de afectos ou perceptos, supera qualquer subjetivismo, tal qual supera qualquer assujeitamento. As forças clandestinas desterritorializam o que antes aparentava a maior solidez. $2+2$ podendo, finalmente, devir 5. E então nos perguntamos: afinal, o que pode o corpo de Artaud?

$\mathrm{Na}$ escrita compulsiva que realiza, o Cso das palavras, recém reanimado, agindo por parições contundentes, desloca-se sob o modo de uma irrupção nômade, dispersiva. A orelha observa, o nariz enxerga, lê-se com outros órgãos, os rostos transbordam seus contornos como em Francis Bacon, criam-se novas sensibilidades. As palavras, ao som do tambor, dos gritos agudos e graves, dançam. "Quelle est la structure (fabrica) d'un corps? La structure d'un corps, c'est la composition de son rapport. Ce que peut un corps, c'est la nature et les limites de son pouvoir d'être affecté"13 (DELEUZE, 2018, p. 198); sabemos com Espinoza que uma ideia que temos indica o estado atual da constituição do nosso corpo; à medida que nosso corpo existe,

\footnotetext{
12 “é reservar o indeciso na decisão, preservar o ilimitado próximo do limite e não dizer nada que não deixe intacto todo o espaço da palavra ou a possibilidade de dizer tudo. E, ao mesmo tempo, é preciso dizer uma coisa apenas e não dizer mais que essa". Tradução do autor.

13 “Qual é a estrutura (fábrica) de um corpo? A estrutura de um corpo é a composição da sua relação. Isso que pode um corpo é a natureza e os limites de seu poder de ser afetado".
} 
ele dura e se define por essa duração afectiva; o que pode um corpo (sua potência), tanto em paixão quanto em ação, é ao mesmo tempo também o seu direito natural. Nas emissões radiofônicas de Artaud, sobrepõem-se vozes diversas que oscilam em se confundirem e provocarem equilíbrios inesperados entre tais potências. As vozes passam por efeitos de modulação, vozes que viram sopros metálicos, xilofones vocais acompanhados por gongos, vibratos de percussão, exacerbações que remetem a estados de transe, ritornelos cruéis. Todos os elementos que compõem a cena performática carregam o rasgo da agitação, do transbordamento, de inevitável pressa e preensão. Sabe-se que as emissões radiofônicas escandalizam os ouvintes da rádio difusão francesa. A emissão mais polêmica certamente foi a de Pour en finir avec le jugement de dieu. Polêmica que já parte do título, cujo duplo sentido é marcado pelo genitivo: ser julgado por deus - esse todo-Outro que bem pode ser chamado de "Deus, Cristo, ou corporificar qualquer instância autoritária, de pensamento e de linguagem: a revolução, Hitler, o PC francês, a guerra ou o próprio líder do movimento surrealista. Um todoOutro que precisa ser evocado e exposto para ser, finalmente, destruído" (BITTENCOURT, 2008, p. 4) - e/ou levar deus a julgamento, esse deus, aliás, grafado insistentemente com a inicial minúscula e que aparece desde "L'ombilic des limbes" como um deus-cadela. Em revolta às paternidades/maternidades, em 1946, em Rodez, Artaud se dizia seu próprio filho, pai e mãe, o niveleur du périple imbécile où s'enferre l'engendrement, le périple papa-maman et l'enfant; "être pèresmères", são "mouvements infinis de figuration-défiguration" 14 (GROSSMAN, 2004, p. 14). Abolir a cruz é terminar de vez com a abjeta coagulação parental papa-mamã (salto radical de $O$ anti-Édipo), é abolir a sagrada família e reverter a ordem lógica das gerações, da culpa entre elas, da reverência e das impressões de enraizamento. A aposta excremental nasce do intuito de eliminação daquilo que contamina o corpo; nesse viés, a palavra emissão não só se limita às intenções radiofônicas em si, mas também confere à poética de Artaud uma decisão semântica que a põe, redobradamente, em prática: são emissões de saliva, esperma, flatulências, merda, fazendo que a insinuação escatológica trabalhe sobre uma dupla potência: combater a sacralidade divina (gesto iconoclasta na dimensão da cultura e do poder simbólico) e combater o organismo orgânico bem estruturado, higienizado, asséptico (gesto coprológico, relativo ao estudo das fezes, no âmbito da escolha das palavras rejeitadas que aparecem como materialidade da arte). As emissões corporais, entonações sólidas no ar, portanto, são marcas da poesia de Artaud: J'ai pété de dérasion et d'excès (Explodi/peidei de desrazão e de excesso).

\footnotetext{
14 "nivelador do périplo imbecil onde se enfurna o engendramento, o périplo papai-mamãe e a criança; 'ser paismães' - são movimentos infinitos de figuração-desfiguração". Tradução do autor.
} 
Reparemos que esses elementos não são trazidos como uma representação de como faz o homem no mundo concreto; eles são, concretamente, na manifestação artística, efetivados, emitidos enquanto novos acontecimentos; não há representação, há, pois, sua superação ${ }^{15}$. Desse modo, avesso ao vocabulário elevado da metafísica do belo, do puro, do apolíneo, Artaud faz da poesia um affaire de sang. Muitas vezes, inclusive, ele destaca no poema (poiêma) a inscrição interna de hema, o sangue. Em carta enviada a Arthur Adamov em 1946, Artaud diz que a poesia deve ser como uma emissão eruptiva, como a erupção de um vulcão como o Popocatepel, uma emissão de lava. Detonar as palavras, destroçar seu fundo divino, torná-las corpos perpetuamente explosivos. Eis o corpo atômico ao qual se refere o poeta, em oposição ao corpo anatômico, o corpo enfermo do homem ocidental, corpo próprio e cadastrado/castrado.

Nos questionamos há pouco, em ressonância atualizada à célebre inquietação espinozista, a propósito do que podia o corpo de Artaud. Ora, a urgência do problema ético por aí se destrava, pois, como diz Espinoza, não sabemos enfim o que pode um corpo, isto é, não sabemos de quais afecções somos capazes, como tampouco sabemos até onde vai nossa potência. Como chegamos a produzir nossas afecções ativas e "un maximum de passions joyeuses ?"16" (DELEUZE, 2018, p. 225). La Recherche de la fécalité, enquanto uma tentativa de inscrição a esse problema, não só explora os recônditos interditados da escatologia, na sua função de escárnio ou de repulsa, mas também se remete a uma pertinente provocação sobre a geração dos corpos (reprodução), no sentido de confundir criação e nascimento anal, porque, no limite, os corpos se reduzem à produção de dejetos, ora defecando seres, ora defecando os

\footnotetext{
15 “Lorsqu'on se met à parler à propos de l'art, d'un rapport à la vie, on ne peut s'empêcher bien sûr de penser à Aristote et à la mimèsis. Mais, avec Artaud, il ne s'agit pas de mimèsis. Pas d'imitation de la vie dans l'art. Il est question de re-créer la vie. Le théâtre n'imite pas, il 'refait la vie'. Ce nouveau langage doit suivre le chemin de la genèse. L'homme ainsi participe à la création. Par l'art, il est un démiurge mais ne se contente pas de refaire ce qui a été fait, il doit retrouver le principe de création même. La pensée d'Artaud, si elle est pour lui très claire peut ne pas l'être tout à fait pour nous. Car, quelle différence faire réellement entre l'imitation de la vie et sa recréation ? Quel est ce chemin de la genèse que l'artiste, le créateur doit retrouver et suivre ? Ce qui est sûr, c'est qu'il n'est pas question d'inventer un semblant de vie, inspiré du réel. C'est la même idée qu'il développe à propos de la peinture. De l'art de Van Gogh, il dit que ce n'est pas "représenter la nature" mais "c'est de la nature nue et pure, la nature vue, comme Cézanne, telle qu'elle est, et non comme Corot, Courbet... telle qu'elle apparaît.")" (ALBERTI, 1999, p. 249). Tradução livre: "Quando começamos a falar a propósito da arte, sobre uma relação com a vida, é claro que não podemos deixar de pensar em Aristóteles e na mimese. Mas, com Artaud, não se trata de mimese. Não há imitação da vida na arte. Trata-se de recriar a vida. O teatro não imita, ele "refaz a vida". Essa nova linguagem deve seguir o caminho da gênese. O homem, portanto, participa da criação. Pela arte, ele é um demiurgo, mas não se contenta em refazer o que foi feito, ele deve redescobrir o próprio princípio da criação. $\mathrm{O}$ pensamento de Artaud, se é muito claro para ele, pode não ser muito claro para nós. Porque qual é a diferença real entre imitar a vida e recriá-la? Qual é esse caminho da gênese que o artista, o criador deve encontrar e seguir? O certo é que não se trata de inventar uma aparência de vida, inspirada na realidade. É a mesma ideia que ele desenvolve sobre a pintura. Da arte de Van Gogh, ele diz que não se trata de "representar a natureza", mas "é a natureza nua e pura, a natureza vista, como Cézanne, tal como é, e não como Corot, Courbet ... como parece ser". 16 “um máximo de paixões felizes?” Tradução do autor.
} 
resíduos corpóreos, ambas formulações encaminhadas ao acontecimento da morte derradeira, a exterior. Ou seja, organicamente, um corpo só pode gerar produtos fadados à morte, ou coisas já mortas. A arte defeca a possível representação do mundo. Isto é, deduzimos com Artaud que de um lado há formas mortas, excrementais (o próprio sujeito é o resíduo das máquinas, dizemnos Deleuze e Guattari, além de já nascer carregando sua própria morte imanente), e, de outro, há um sopro explosivo que habilita o Cso a produzir a arte que resiste, que, devido à vitalidade inorgânica, sustenta-se por si só. A obra de arte é aquela que de repente se sustenta sozinha. No caso de um Cso, a anatômica e divina hierarquia dos orifícios é abolida à medida em que o ânus toma para si a potência de uma boca e o poeta se expressa aos peidos, sem nada imitar, eis o aparelho blasfematório que Artaud desenvolve contra aqueles que insistem em creditar a poesia ao sublime. “O ânus é sempre terror” (DELEUZE, 2015, p. 87), dirá o autor. Surge em Artaud uma forma-buraco (forme-trou) que mostra ao mesmo tempo que o buraco é também uma forma e que é preciso esburacar as formas para extrair das criptas o segredo, dupla relação que evidencia as falhas entre o encontrado (trouvé) e o esburacado (troué), entre a face e o rosto, perfurações para deixar em suspenso (GROSSMAN, 2004, p. 22). Processo assignificante, poesia a-literária de escavação larvar. Poesia em processo (em devir) de fazer-se literatura?

O que resta depois de uma explosão, de uma erupção? Fragmentação (esquizo), dissipação. Pedaços, partes em miniatura, quebra-cabeça das carnes a ser remontado. Faltam peças, contudo. No lugar das convencionais, aparecem outras, outros encaixes, nova distribuição. O xilofone remendado toca a anomalia que risca o tímpano. É preciso então escutar com os olhos. O corpo esquizofrênico é sonoro e reverte o diagnóstico psiquiátrico. Onde estarão os verdadeiros médicos da civilização, no entanto? Vouz délirez, monsieur Artaud. Vous êtes fou ${ }^{17}$. Citemos um po-hema de Artaud (2003, p. 23), para perfurarmos sua materialidade:

$\begin{array}{lll}\text { kré } & \text { Il faut que tout } & \text { puc te } \\ \text { kré } & \text { soit rangé } & \text { puk te } \\ \text { pek } & \text { à un poil près } & \text { li le } \\ \text { kre } & \text { dans un ordre } & \text { pek ti le } \\ \text { e } & \text { fulminant } & \text { kruk } \\ \text { pte } & & \end{array}$

Esse poema, ou fragmento de poema, espécie de apresentação ou epígrafe, abre Pour en finir avec le jugement de dieu. Ao que tudo indica, devemos lê-lo de maneira horizontal, linear, como de costume, para extrair efeito dos ruídos. O núcleo dos versos, ainda verbal, é

\footnotetext{
17 "Você delira, senhor Artaud. Você está louco." Uma possível tradução livre da parte central do poema que vem na sequência: "É preciso que tudo seja organizado muito próximo de uma ordem fulminante".
} 
centralizado no espaço da página, sendo precedido e sucedido pelos elementos semanticamente assignificantes, que sugerem, aliás, uma distribuição em formato de conjugação de verbo, no lado direito, formando seis colunas como se fossem seis pessoas ocultas: eu kré, tu kré, ele pek, nós kre, vós $e$, eles pte. Tais marcações sonoras, guturais e maquínicas aparecem em negrito, denotando certo destaque em relação à enunciação que alerta que é preciso que tudo seja guardado muito próximo de uma ordem fulminante. Parece, portanto, pouco efetiva a tentativa de tentar decifrar o que dão a entender ou o que podemos interpretar a partir das glossolalias ${ }^{18}$ que, além de insinuarem o limite de uma língua estrangeira própria a Artaud, operam a produção de uma melodia exclusivamente sonora - sopro sonoro em forma de palavra - que abre, fecha e acompanha o andamento da composição. O som é expelido à medida que envolve a ordem das letras em uma atmosfera fulminante que, por sua vez, torna-se tautológica ao ser realizado o ato da leitura em voz alta. O olho ouve o rangido das máquinas. As palavras dançam entre os pilares meramente fonéticos que as sediam, e mesmo, se o jogo deve perpassar o som, as assediam. Assédio do som-ruído de fora à letra que segue a sequência que lhe compete sentido; a palavra em Artaud, plástica e física, demanda a oralização enquanto um empreendimento; tal maneira-de-palavra retumba o signo primitivo territorial dos sauvages de $O$ anti-Édipo que “ignore la subordination linéaire et sa réciprocité : ni pictogramme ni idéogramme, il est rythme et non forme, zigzag et non ligne, artefact et non idée, production et non pas expression"19 (DELEUZE; GUATTARI, 2018, p. 244). A emissão começa, não à toa, com uma explosão.

Artaud, a seu modo digestivo e fecal, em "retorno à animalidade e ao prazer sofisticado do abjeto" (BITTENCOURT, 2008, p. 6), atualiza a tradição contingente dos escritores escatológicos, muitas vezes tidos como pornográficos, subversivos e malditos. Das nauseabundas latrinas cotidianas à l'épreuve dite de la liqueur séminale ou du sperme [a prova dita do licor seminal ou do esperma], toca as entranhas de uma linguagem proibida, gástrica, repelida por sua crueza real e viscosa. Em meio a essas superfícies, o delírio nasce da terra, da terra em constante e vertiginosa desterritorialização, mudança e movimento; Artaud é antes de tudo geológico/geosófico, daí a ressonância complementar a Nietzsche na "Geologia da moral" em Deleuze e Guattari. La terre se peint et se décrit / sous l'action d'une terrible danse / à qui

\footnotetext{
${ }^{18}$ Em Enlouquecer o subjéctil, Derrida e Norma Bergstein (1998) explicam a glossolalia: "um monte de palavras possíveis [que] fervilham sob a superfície, prontas a emprenhar ou a reprimir a chamada língua natural para livrarse dela" e refere-se, ainda à "glossolalia dos profetas [que] supostamente 'falava em línguas'; afirmava-se que era imediatamente acessível aos sujeitos de línguas diferentes, universalmente inteligível antes de qualquer tradução, como se supõe por ingenuidade da pintura ou do desenho" (Apub BITTENCOURT, 2008, p. 7).

19 "ignora a subordinação linear e sua reciprocidade: nem pictograma nem ideograma, ele é ritmo e não forma, zigzag e não linha, artefato e não ideia, produção e não expressão". Tradução do autor.
} 
on n'a pas encore fait donner / épidémiquement tous ses fruits [A terra se pinta e se descreve / sob a ação de uma terrível dança / que não se fez dar ainda / epidemicamente todos os seus frutos]. Os interstícios das fezes e dos fluidos aparecem em Artaud sob sua acepção mais natural possível: os excrementos, o sangue, os pruridos do corpo são tão naturais na animalidade humana quanto é natural - espontânea, primitiva, pré-individual - a dimensão do delírio. Do contato com o fora, do sair de si: defecar também pode ser visto como uma forma de transcender. Por uma poesia que descarta, subtrai, antes de mais nada o elevado, o elegante, o fetiche intelectual e a sobrecarga erudita. Deleuze (2011a) aponta outros três aspectos em Artaud que passam a interessar: 1) a omissão das letras na decomposição da linguagem materna (lembremos que Artaud diz ser seu pai e sua mãe, nunca sendo daqui, negando sua afiliação com a terra e com a língua francesa, os lo he dicho, no tengo ya mi lengua ${ }^{20}$ ); 2) a retomada das letras omitidas numa nova sintaxe, criadoras de uma língua estrangeira dentro da língua ${ }^{21}$ (a relação com os povos ameríndios é essencial a esse trânsito que põe em transe) e 3) a criação das palavras-sopro: limite assintático para onde flui toda linguagem quando tensionada, ou seja, as palavras-sopro são arrancadas da língua-pátria em direção ao fora, às migrações mais extemporâneas.

Na sequência desses sentidos, não poderíamos deixar de elencar a relação da linguagem com o ato de comer, da vida enquanto nutrição, a consequente busca e produção da fecalidade e a sua extrapolação ao retornar na operação de uma linguagem-outra. A língua, além disso, é também a carne, o órgão-língua que sofre as consequências: Quita tu lengua, mi lengua, mi lengua, mierda (...) más allá, más allá, Espíritu, Espíritu, fuego, lenguas de fuego, fuego, fuego, come tu lengua, perro viejo, come su lengua, come, etc. Arranco mi lengua ${ }^{22}$. Em Artaud, “o rito do peyote afronta as letras e os órgãos, mas para fazê-los passar para o outro lado, nos sopros inarticulados, num indecomponível Cso" (DELEUZE, 2011b, p. 28); os órgãos, cancerosos, levam à morte. Uma das reações do peyote é a reversão temporária do

\footnotetext{
20 “eu lhes disse, já não tenho minha língua". Tradução livre. Texto de Le Pèse-Nerfs, Artaud (2014, p. 70).

${ }^{21}$ Exemplo dessa supressão e novo deslocamento está na passagem do "Le Théâtre de la Cruauté", poema de Pour en finir: "ko embach / tu ur ja bella / ur ja bella / kou embach / Lá, les vivants s'y donnent rendez-vous avec les morts / et certains tableaux de danses macabres / n'ont pas d'autre origine" (ARTAUD, 2003, p. 74). Outro trecho significativo sinaliza a decomposição da língua francesa quando Artaud nega seu batismo cuspindo sobre cristo e provocando uma catástrofe que se dirige à cruz, mas que ressoa na língua, na criação da língua estrangeira nos États préparatoires nI da "Recherche de la fécalité”: "je renie le baptême, / je crache sur le christ / aussi peu inné qu'il en est profondément inique et réprouvé, / j'abjecte le signe obscène et catastrophique de la croix. / priur / fantisch / tru / stru / strastsa / tas belle / strsa / tasbelli / ta / fra / la / la" (ARTAUD, 2003, p. 141).

22 "Tira tua língua, minha língua, minha língua, merda (...) mais além, mais além, Espírito, Espírito, fogo, línguas de fogo, fogo, fogo, come tua língua, cachorro velho, come tua língua, come, etc. Arranco minha língua. Tradução do autor. "Pablo Pájaros o El lugar del amor", texto de L'ombilic des limbes, Artaud (2014, p. 20).
} 
funcionamento padrão dos órgãos, ou seja, os fluxos comuns se reorganizam noutros encaminhamentos, tomam outras direções, ocasionando efeitos antes insondáveis, que, por sua vez, passam por vômitos, espasmos, retrações musculares. Acerca das letras, toda a história do fluxo gráfico “va du flot de sperme au berceau du tyran, jusqu'au flot de merde dans sa tombeégout, - 'toute l'écriture est de cochonnerie', toute écriture est cette simulation, sperme et excrément" 23 (DELEUZE; GUATTARI, 2018, p. 254). Certa combinação entre as palavrassopro e o Cso nos faz fugir de qualquer língua, identidade ou sistematização orgânica, devido ao caráter máximo de inarticulação promovido nesse encontro. Curioso paradoxo entre combinação (encontro afectivo) e inarticulação extrema. Ahora tendría que hablar de la descorporización de la realidad, de esa especie de ruptura aplicada ${ }^{24}$. O Cso, opondo-se à sistemática dos órgãos, é o acontecimento do indecomponível por si mesmo; de intensidade $=$ 0, ele já não tem geração, ou seja, nada é reproduzido a partir dele, assim como nada por ele é representado - o que Artaud mais odiava, para dizer o óbvio, era a ideia de representação. Sendo assim, é preciso restituir na arte o corpo assassinado de um Van Gogh suicidado pela sociedade $^{25}$. É urgente abandonar os órgãos de origem e então criar a própria origem para si. Mas como fazer isso sem se entregar à mera alucinação, ao jogo metafórico das palavras, digase de passagem, megalomaníaco?

O que evita o mergulho numa abstração vertiginosa, negativa ou vazia, é tão-somente o gosto pela aventura, afinal, “o que é a vida senão sua aventura?” (DELEUZE, 2011b, p. 32). Parece ser essa uma saída ordinária, que se opõe ao saber, inclusive; entretanto, não se trata disso. Tanto para Artaud como para Deleuze, a vida não se contrapõe ao saber, seria injusto recair nesse recorrente embuste, pois, para ambos, são as dores mais intensas que dão

\footnotetext{
23 "vai do fluxo de esperma ao berço do tirano, até o fluxo de merda em seu túmulo de esgoto, - 'toda escrita é uma porcaria', toda escrita é essa simulação, espera e excremento". Tradução do autor.

24 "Agora teria que falar da descorporalização da realidade, dessa espécie de ruptura aplicada". Tradução do autor. "Descripción de un estado físico", texto de L'ombilic des limbes, Artaud (2014, p. 27).

${ }^{25}$ Van Gogh le suicidé de la Société é o célebre ensaio poético e autobiográfico de 1947 em que Artaud destaca a lucidez fora do comum do pintor impressionista, vexatória à sociedade da época que o exclui gradualmente em função das verdades insuportáveis que sua pintura revela, levando-o ao exílio interior, à automutilação e ao suicídio - ou, melhor dito, à condição de vítima de um assassinato. A crítica à psiquiatria ganha relevo nesse contexto, servindo como um desastroso e inestimável nexo entre a vida dos dois artistas. De todos os modos, é aqui que a oposição ao corpo anatômico e ao racionalismo que o emoldura se desloca ao âmbito poético, encontrando Van Gogh e seu corpo atômico, fragmentado, forçadamente traumatizado, febril, que, além de ameaçar à sanidade representativa da pintura a partir de suas paisagens em convulsão, dá mostras de como a grande arte resiste às imposturas do academicismo, da tradição e das instituições de juízo. A criação de Van Gogh, segundo Artaud (2001), surgia da intuição, da sensação; ela ultrapassa a pintura como meio estrito para sua obra, ultrapassando, por extensão, a pintura em si, que tem como princípio o ato inerte de representar a natureza. A nova linguagem que Artaud busca aposta, portanto, na eficácia vitalista dos órgãos vencidos sobre o homem que vê seu domínio escapar frente às resistentes forças poéticas que, por sua vez, reivindicam a restituição dos corpos suicidados.
} 
primeiramente um estranho apetite de saber aos que as experimentam, e o que passa a ser o saber (o que inclui a sensação, a intuição, o afecto, a maquinação ética, a demanda política, a justiça para com o menor) senão a aventura da vida dolorosa na animalidade do cérebro que se nutre de provação, modificação e atividade empírica? Viver na aventura é evitar a acomodação, combater a tirania sobre os corpos, estar em movimento, certamente, mas não só; não se trata de um movimento descabido, inoperante, aleatório, esvaziado de saber. O corpo de Artaud é o corpo inato do homem. Artaud é um homem sem pertenças, em constante desintegração, desfiguração: ni mi grito ni mi fiebre me pertenecen ${ }^{26}$. As palavras-sopros aparecem como sustentações unívocas para uma arte que se relaciona intimamente com a liberdade préindividual, com essa imanência intransigente que provoca a sedição aos organismos antropocêntricos: "me hablan de palabras, pero no se trata de palabras, se trata de la duración del espíritu ${ }^{27}$ " (ARTAUD, 2014, p. 83). O devir da linguagem prepara o corpo por vir das palavras que contarão histórias de amor, de dor e loucura, por onde vida e saber não mais travam guerra entre si; porém, essas narrativas verbais ou fora do verbo, não estão significadas pelas palavras, não são transferências de sentido de uma palavra à próxima; essas histórias são antes o que há de impossível na linguagem e pertence mais substancialmente à linguagem ante sua virtualidade íntima-imanente de produção de produções; esse estilo impossível ainda da linguagem, esse segredo sensível, imperceptível, é o seu próprio fora. O problema nunca se tratou de ultrapassar as fronteiras da razão e lá, desse outro lado tão oculto, instalar-se; Artaud, melhor que qualquer procedimento psicótico, mostra como o problema é o de atravessar como vencedor as fronteiras da déraison; vencer, nesse caso, é adquirir a potência do movimento liberado, libertário, a aceleração pensante que vai à loucura, mas sabe voltar, a irresistível saúde da escrita.

Por uma história do impossível na linguagem: Artaud desvela a clandestina história do sopro (anima, princípio vital para os romanos, o sopro da vida) e do corpo inato do homem. Do corpo que se cria em vida. A aparente negação da determinação do nascido pelo Cso é na verdade uma pulsão afirmativa do fora, do inacabamento - a literatura está antes do lado do inacabamento para Deleuze; um ponto final é antes um abortamento do processo, nunca a definição de um resultado - maneira distinta de dizer o devir. A história do impossível na linguagem é também a história do processo do impossível como tendência ao novo possível, ou

\footnotetext{
26 "Nem meu grito, nem minha febre me pertencem". Tradução do autor. Texto de Fragments d'un Journal d'Enfer, Artaud (2014, p. 79).

27 "me falam de palavras, mas não se trata de palavras, se trata da duração do espírito". Tradução do autor.
} 
seja, são os percursos dos devires inauditos que outra vez se destaquem. Uma sintaxe em devir dá realidade a uma gramática do desequilíbrio. Nisso consta a relação da língua com o gaguejar. Contudo, o estado bruto desse acontecimento agramatical ocorre em Artaud através do manejo intensivo das palavras-sopro em direção a novas curvaturas sintáticas que são efetivas variações afectivas. Essas puras intensidades marcam um limiar da linguagem, espécie de membrana cósmica com a vida, que faz dançar as palavras na letra escrita, mas quem também faz gaguejar seus aspectos fônicos, de mancha, extrações audíveis e também colorantes.

$\mathrm{Na}$ matéria literária, portanto, presenciamos uma correlação entre tensionamento e limite. A tensão se dá, de fato, na língua (a gagueira, o balbucio), à medida que a zona de limiar, a sutil membrana conectora, aparece à linguagem. Sobretudo é importante aprender a passear por essa linha nevrálgica que é responsável pela carícia amorosa com o fora. Sem isso, como a pele (essa instância mais profunda do corpo, segundo Valéry) respiraria? O texto é epidérmico, as peles são hipersensíveis, vemos nos relatos de Sacher-Masoch, mas quem nos mostra que as peles, por sua natureza de contato, de fricção, são sujas, é factualmente Artaud. As peles só se tornam assépticas por meio das intervenções artificiais, que visam à padronização dos corpos através do afastamento programático do humano de sua dimensão animal. A busca pelo Cso perpassa invariavelmente à esfera do devir-animal. E é nesse sentido que a imundice revelada por Artaud encontra sua ressonância primitiva, sua forma de inscrição num plano de natureza que alude às composições pré-individuais. Ademais, é preciso levar em consideração que todos esses elementos ou índices dos compostos impessoais, ao que concerne uma concepção imanente e virtual, não estão completamente fora de nós, fora da arte, fora da expressão humana de maneira geral. Se as palavras então regurgitam seus conteúdos, o que vem à tona são seus traços mais íntimos, que se criam, ganham uma nova luz, de acordo com os agenciamentos inesperados, que fazem as mesmas palavras de sempre - sob uma delirante repetição diferencial - pintarem e cantarem. É disso que se trata a esquizofrenia enquanto estilo. Ser o fora não é estar fora, parece ser o que Artaud nos quer gaguejar à boca de um ouvido que vê. E, de repente, além do pântano de terra movediça das multiplicidades agindo sobre as palavras, essas, acontecimentalmente, depois de manchas de tinta ou escritas ilegíveis, encontram um silêncio bastante arrebatador. Um silêncio ainda repleto de ideias, angustias e potências de palavras, é certo, pois, depois do primeiro Silêncio, todo silêncio está povoado de signos. Todo silêncio (segundo e possível), sendo assim, é uma busca já frustrada pela impossibilidade sensitiva desse Silêncio inaugural, que talvez nunca tenha havido. "Quando a língua está tão tensionada a ponto de gaguejar ou de murmurar, balbuciar..., a linguagem inteira atinge o limite que desenha o seu 
fora e se confronta com o silêncio" (DELEUZE, 2011c, p. 145). A linha nevrálgica, portanto, mostra suas duas faces que combatem e atravessam as palavras: a face do som inusitado que antes nas palavras não aparecia, e a face do silêncio polivalente que tal qual agora acontece.

Mas como fazer o silêncio na literatura sem reduzi-lo a um espaço meramente gráfico, a um muro branco ou buraco negro? Por que as palavras, mesmo após tantas erupções, tendem a voltar ao silêncio e a nos deixar em silêncio, que sobretudo é um silêncio outro? Quando acaba a palavra poética, o livro, o que fala em nós após o intervalo acontecimental do silêncio? Parece-nos cabível ensaiar ao menos um vetor para tais entroncamentos: talvez mais do que pudessem dar a entender outras concepções teóricas, esses são problemas que estão ligados singularmente a uma instância física que repele o conjunto de estratagemas da mímese enquanto lei-molar literária. Espinoza comenta as fisicalidades intempestivas: tudo é "físico" na natureza, "physique de la quantité intensive (...) physique de la quantité extensive (...) physique de la force, c'est à dire, dynamisme d'après le quel l'essence s'affirme dans l'existence, épousant les variations de la puissance d'agir"'28 (DELEUZE, 2018, p. 213). De todos os modos, quando a língua está tensionada, a linguagem sofre uma pressão que a devolve ao silêncio. Um silêncio, contudo, que não se configura como fim. Ou seja, não se trata de maneira alguma de um fim da arte, morte da literatura, ou nada que o valha; é como afirma Carine Alberti (1999, p. 242): “dans ces allégations qui semblent rejeter l'art, c'est en réalité un refus de l'art pour l'art, de l'art trouvant sa fin dans l'œuvre d'art qu'exprime Artaud"29. O gaguejo envolve enfim três passeios, que de Artaud a Beckett vemos prosperar defronte a marca do esquizofrênico que se desloca: um passeio aos limites, às fronteiras da gramaticalidade, aos limiares do estético, às margens da loucura e do delírio assignificante; um passeio ao fora (das estruturas, da letra correta), ao imperceptível, ao inaudível, ao segredo; e um passeio ao silêncio, ao campo de forças que prepara o desejo para recomeçar sempre do meio, silêncio atemporal, matéria de duração/sedução, abertura à chance do novo. Três passeios pelos quais, como as palavras que em literatura servem a eles como materialidade transcendental, aprende-se à cada atualização a embaraçar melhor, no sentindo dúbio entre o português e o castelhano de confundir e engravidar, co-fundir, gestar devires sob gestações sem pais. Devir-criança sem eu algum, gestar sem reproduzir, por abortos, devir tão-somente em relação intrínseca com a força de

\footnotetext{
28 “física da quantidade intensiva (...) física da quantidade extensiva (...) física da força, ou seja, dinamismo posterior à essência que se afirma na existência, juntando as variações da potência de agir". Tradução do autor. 29 "nessas alegações que parecem rejeitar a arte, sucede, na realidade, uma recusa da arte pela arte, da arte que encontra seu fim na própria obra da arte, exprime Artaud". Tradução do autor.
} 
resistência da infância. Lyotard (1991) chamava de infância o fenômeno de arrastar a língua a seus limites vertiginosos: infantia, o que não se fala; o que não se deixa escrever no escrito faz apelo a um leitor que desaprendeu, ou ainda, não aprendeu, a ler. Todos carregamos esse leitor - mesmo em silêncio - dentro de nós. O que mesmo pode a imanência de Artaud?

As dobras de Artaud nos arrastam e nos fazem retornar definitivamente da mais explosiva catástrofe ao mais inescrutável silêncio que sucede o murmúrio poético. Não há caminho algum para seguir nesse choque de abortos sem imagens, sem sentimentos. Blanchot (2005) observa Artaud a partir da condição contínua de sofrimento que o leva a um legítimo abandono do pensamento no próprio pensamento. Esse abandono, certa ausência cognitiva desenvolvida em função da dor, provoca um perceptível descuido gradual com as formas, que, no seu próprio modo enviesado de ver, foram sempre insuficientes. Seus poemas, sendo assim, tem a carga do defeituoso, do deformado, de-formosus. Acomete-lhe o grande fervor pensante e superpovoado que leva o seu eu ao abismo pleno, ao "Umbigo dos limbos". O fracasso, na chave blanchotiana, aparece então como um signo sensível desse acontecimento literário; atraente, extravia o elo entre moral e julgamento. É notório que Artaud busque salvar seu pensamento perdido através do processo de erosão que o entrega à escrita. Ou seja, o pensamento como uma extensão do fecal, encontra-se perdido, mas há resíduos dessa força de resistência pensante que devêm ainda na escrita poética e/ou ensaística. Interessa, entretanto, muito mais o fato de que Artaud descobre, à maneira empírica, que pensar não é exclusivamente ter pensamentos. Os pensamentos que Artaud "tem" só o fazem sentir que ele ainda não começou a pensar. Pensar é sempre não poder pensar ainda. Ora, eis aí o mais sofisticado impoder. Ao consumir a substância física do que pensa, essa se divide a todos os níveis de impossibilidades singulares. Essa divisão diferencial, essa erosão criativa, que parte da cisão do ser, encontra invariavelmente a defecção. A busca da fecalidade ganha rigor em meio aos efeitos da nutrição - do ato de devorar com obsessão - da matéria pensante, que, por sua vez, ao invés de se tornar pensamento concreto enumerável, é desconfigurada pelo aparato digestivo da poesia gástrica, não mais sequer tornando-se, mas apenas devindo. Por isso muitas vezes a grande poesia de Artaud não chegou ao papel. Noutras vezes, sequer foi de algum modo manifestada, isto é, permaneceu sem maneira ${ }^{30}$, sem gesto, sobrevivendo somente em termos

\footnotetext{
${ }^{30}$ Uma distinção semântica (semantemas existenciais, com diz Lapoujade) a ser levada em consideração engendra a importância do gesto: "modo y manera no designan completamente lo mismo. Forzando la distinción, diremos que el modo (de modus) piensa la existencia a partir de los límites o de la medida de los seres (como lo testimonia la derivada moderación), mientras que la manera (de manus piensa la existencia a partir del gesto, de la forma que toman los seres cuando aparecen. El modo delimita una potencia de existir mientras que la manera revela su forma,
} 
de virtualidade, ou sob a espessura do repentino balbucio: "je ne sais parler, / quand je parle je bégaye parce qu'on me mange mes mots"31, sopra-nos Artaud (Apud BOUILLON, 2016, p. $11)$.

Como insiste Blanchot, o impoder da defecção nunca é resultado de uma felicidade. Tampouco de um alívio duradouro às crises, como se emulasse à paz do ópio do qual, em inúmeras ocasiões, Artaud precisou se desintoxicar. A poesia, para a imanência sem órgãos, é, portanto, dor perpétua. Mas a dor que Artaud sente não é em específico a dor individual - a despersonalização de Artaud segue, por ora, a mesma contingência da qual faz parte Pessoa (em 1937, Artaud decide que seu nome deve desaparecer) -, trata-se, todavia, da dor que só os grandes escritores sentem, e que os torna médicos da civilização, a dor do devir do mundo, parto sem reprodução. Nietzsche, Artaud, tantos outros: é por serem diferencialmente enfermos que jogam sobre o próprio corpo o instinto secreto da grande saúde; estar doente, como eles estiveram, é ver o quanto o mundo vai mal, fato que, com efeito, poucos realmente veem. É preferível devir-louco do que se contentar com a grosse saúde dominante de um mundo ignorante da própria doença. Sombra, noite das almas, ausência de voz para gritar. Daí o começo da relação de Artaud com o nada, pois há indícios desde suas primeiras produções de que, em literatura, ele apenas poderia dizer que nada poderia escrever em absoluto. Contudo, bem sabemos, que sempre escreveu exaustivamente para dizer que nada poderia escrever, que jamais fez nada e que mesmo fazendo algo (a poesia), nada fazia. A obra de Artaud disserta implicitamente sobre um jogo de forças com o nada. Será a tarefa de Artaud (2014, p. 37) sobrecodificar o nada, "la verdadera nada deshilada, la nada que no tiene ya órgano"? ${ }^{32} \mathrm{O}$ empreendimento da nulidade radical tensiona a matéria que provoca o representável, e a palavra, infernizada por sua assignificância, aparta-se de modo gradual das palavras que dizem algo. Quem nada tem a dizer, acaba por se esforçar mais em começar a se expressar do que propriamente se expressa. Com efeito, germina-se aí uma relação insólita e ao mesmo tempo íntima com a dimensão do ensaio. Tudo que Artaud escreve (supostamente nada) é um ensaio para uma escrita por vir que não será efetivada por ele, apesar de que esse ensaio sem fim (devir)

\footnotetext{
su línea, su curvatura singulares y con ello da testimonio de un 'arte"” (LAPOUJADE, 2018, p. 14). Tradução livre: "modo e maneira não designam completamente o mesmo. Forçando a distinção, diremos que o modo (de modus) pensa a existência a partir dos limites ou da medida dos seres (como testemunha a derivada moderação), enquanto a maneira (de manus, pensa a existência a partir do gesto, da forma que tomam os seres quando aparecem. O modo delimita uma potência de existir, enquanto a maneira revela sua forma, sua linha, sua curvatura singulares e com isso fornece o testemunho de uma 'arte","

31 "Eu não sei falar / quando falo, eu gaguejo, porque como minhas palavras". Tradução do autor.

32 “O verdadeiro nada desfilado, o nada que já não tem órgão". Tradução do autor.
} 
seja muitas vezes expressado virtualmente na escrita. O que em princípio mais parece uma atitude de defesa, no sentido de que isso que escrevo não vale nada porque o que vale ainda está por vir, mostra-se, surpreendentemente, como uma estratégia combativa. É por essas vias que Blanchot conclui que em Artaud, no limite, não há língua nem obra, há apenas um belo pesa-nervos, título de uma de suas obras mais relevantes, Le Pèse-Nerfs, de 1925. Blanchot e Deleuze aparentemente discordam nesse ponto, pois se o Artaud de Blanchot não tem língua nem pensamentos, o Artaud de Deleuze é um dos resplendores da criação da língua estrangeira dentro da língua, além de ser o gatilho nerval para a acepção do pensamento sem imagem. Ainda na esteira de Blanchot, Artaud assume a posição de vítima da ilusão do imediato. Levando tal ilusão em conta, garante-se que tudo começa em Artaud a partir de sua condição de apartado do imediato, leia-se, na chave blanchotiana, da vida. No primeiro lugar, desse modo, Artaud instala a despossessão, o conjuro - a merda expelida, a morte da promessa de nutrição. O conjuro digestivo dessa escrita é o revés da totalidade imediata e da enfermidade, da plenitude do ser ou da sua queda; ora, Artaud, em meio à rotina dos hospícios, foi impedido de viver a existência do impulso do presente, não à toa sua vida é nitidamente um caso de devir.

Uma fissura ontológica, digamos, adentra a corrosão de seu processo: o ser surge senão como a carência do ser, uma nova fome. Tal carência viva é inapreensível e inexpressável, salvo pelo sopro de uma feroz abstinência. Ainda que esse salto nadificatório possa dar a entender que se expressa em Artaud uma reparação teleológica ao nada, não é isso que sucede. Trata-se, melhor dito, de uma escrita contra a proliferação infinita do vazio e da nulidade sobre o ser em inescapável fissura. Artaud mostra como é possível combater o vazio com o vazio, subtraindose ao nada; em seguida a esse combate, escreve se expondo, nu e relaxado, ao vazio, extraindo dele expressão, superando o ponto de ausência, de inanidade, e, inclusive, de morte. Ou seja, algo daí nasce. Blanchot, nesse aspecto, antecede a observação deleuziana que conhecemos: em Artaud, há antes as descrições de um combate extensivo (contra deus e o organismo, contra o vazio e o nada) do que a análise de estados psicológicos que perpassam o eu. Depois da exigência de uma negação mais decisiva, tudo volta a começar. O mesmo movimento ocorre na defecção e na nova alimentação, na decantação, como diz Artaud em Le Pèse-Nerfs, na desterritorialização e na abertura inevitável à nova reterritorialização. Me habla de Narcisismo, le contesto que se trata de mi vida. No creo en el yo, pero sí en la carne, en el sentido de la palabra carne ${ }^{33}$. Salienta Blanchot $(2005$, p. 62), o que diz Artaud "posee una intensidad que

\footnotetext{
33 "Me falam de Narcisismo, eu contesto que se trata da minha vida. Não acredito no eu, mas sim na carne, no sentido da palavra carne". Tradução livre. Texto de Fragments d'un Journal d'Enfer, Artaud (2014, p. 82).
} 
no deberíamos soportar. Aquí, habla un dolor que rechaza toda profundidad, toda ilusión y toda esperanza, pero que, con ese rechazo, brinda al pensamiento "el éter de un nuevo espacio""34. Ler Artaud é aprender que pensar é perturbador. Sendo assim, sofrer e pensar estão ligados de maneira secreta: ambos, levados ao limite, destroem-se a si mesmos, e o que resta disso, se a arte resistir por si só, é a matéria escrita que permanece e finalmente chega.

A imbricação entre vida e literatura é tão crucial para Artaud que podemos dizer que sua vida já está dentro da literatura - não é uma extensão, tampouco uma transposição, uma imitação ou um arranjo do biografismo -; é estando-já-dentro da literatura, questão obviamente de imanência e de devir-imperceptível, que Artaud nutre sua vida do espaço literário, come as palavras, e finalmente pode afirmar: não se morre, ao menos aqui ou assim. Depois das palavras devoradas por devires imprescindíveis da infância ao animal, do louco-esquizo à dérasion menor, restam os sopros, o fogo do pensamento. O balbucio, o gaguejo, aparecem como o suplício da linguagem que se rebate, encaminhando um estilo de protesto que se usa do corpo que não suporta o ser sem explodi-lo. Uma batalha de corpos que se arriscam a pequenas mortes: a batalha faz balbuciar a voz; à medida em que as palavras fogem, a linguagem parte alhures e se parte, ainda que Artaud não se reduza ao silêncio, apesar de, como ninguém, saber provocá-lo no rasgo das urgências. Artaud tem o direito de falar. Sua desterritorialização da linguagem é também uma deposição jurídica da mesma, fato que eleva Artaud a uma consistente personagem-conceitual para Deleuze, no sentido de que, lembra Lapoujade (2018, p. 19), tal noção invoca "rasgos relacionales, dinámicos o existenciales, pero, también y sobre todo, rasgos jurídicos”35. A que isso induz? Decerto à questão que Artaud conviveu pela maior parte da vida: com que direito pretendes existir? O que legitima a velocidade, a inscrição e a posição da existência? "Cada nueva entidad filosofica, pero también cada forma de existencia, artística, científica, existencial debe hacer la prueba de su validez. Para 'situarse', deben vencer ellas también la duda, el esceptismo o la denegación que les discute el derecho de existir" ${ }^{\prime 36}$ (LAPOUJADE, 2018, p. 20). Criar passa a ser o mesmo que testemunhar. Se "testimonia siempre en favor de la 'belleza del mundo', en favor de su inteligibilidad y de su 'cosmicidad'

\footnotetext{
34 "possui uma intensidade que não deveríamos suportar. Aqui, fala uma dor que rechaça toda profundidade, toda ilusão e toda esperança, mas que, com esse rechaço, brinda o pensamento com 'o éter de um novo espaço"”. Tradução do autor.

35 "rasgos relacionais, dinâmicos ou existenciais, mas, também e sobretudo, rasgos jurídicos". Tradução do autor.

36 "Cada nova entidade filosófica, mas também cada forma de existência, artística, científica, existencial deve provar sua validade. Para 'se situar', devem vencer também a dúvida, o ceticismo ou a denegação que discute seu direito de existir”. Tradução do autor.
} 
revelando en él nuevos seres. (...) Hacer ver es, en ese sentido, tomar como testigo",37 (LAPOUJADE, 2018, p. 77). Testemunho e tradução vistos fora da mímise imagética.

A condição agramatical da poesia de Artaud será, portanto, a reinvindicação singular desse direito, direito inclusive de testemunhar-se/traduzir-se sem a imagem de um eu ou de um si representativo, assim como o gaguejo atingirá a disposição de um ritornelo político. Artaud é o testemunho da univocidade que não necessita ser-eu-mesmo.

\section{REFERÊNCIAS}

ALBERTI, Carine. Antonin Artaud : Tentatives et apories d'une réflexion sur l'art. Paris, Le Philosophoire 1999/1 ( $\left.\mathrm{n}^{\circ} 7\right)$, pages 242 à 251.

ARTAUD, Antonin. Pour en finir avec le jugement de dieu. Paris: Éditions Gallimard, 2003.

ARTAUD, Antonin. Van Gogh le suicidé de la société. Paris: Gallimard, 2001.

ARTAUD, Antonin. L'Ombilic des Limbes, Le Pèse-Nerfs y Fragments d'un Jornal d'Enfer. Traducción de Marcos Barnatán. Madrid: Visor Libros, 2014.

ARTAUD, Antonin. O teatro e seu duplo. Tradução de Teixeira Coelho. SP: Martins Fontes, 1999.

BITTENCOURT, Rita Lenira de Freitas. Abaixo o dedo de deus e os números redondos: performance surrealista e escritura do presente. Tubarão, SC: Unesul, Crítica Cultural, v. 3, número 1, jan./jun. 2008.

BLANCHOT, Maurice. El libro por venir. Tradução de Cristina de Peretti y Emilio Velasco. Madrid: Editorial Trotta, 2005.

BOUILlON, Anne. Gilles Deleuze et Antonin Artaud: l'impossibilité de penser. Paris: L'Harmattan, 2016.

DELEUZE, Gilles. Para dar um fim ao juízo. In: Crítica e clínica. Tradução de Peter Pál Pelbart. São Paulo: Editora 34, 2011.

DELEUZE, Gilles. Spinoza et le problème de l'expression. Paris: Les Éditions de Minuit, 2018.

DELEUZE, Gilles. Lógica do sentido. Tradução de Luiz Salinas Fortes. São Paulo: Perspectiva, 2015. 37 “testemunha sempre a favor da 'beleza do mundo', a favor da sua inteligibilidade e da sua 'cosmicidade'
revelando nele novos seres. (...) Fazer ver é, nesse sentido, tomar como testemunho. Tradução do autor. 
DELEUZE, Gilles. A literatura e a vida. In: Crítica e clínica. Tradução de Peter Pál Pelbart. São Paulo: Editora 34, 2011 a.

DELEUZE, Gilles. Louis Wolfson, ou o procedimento. In: Crítica e clínica. Tradução de Peter Pál Pelbart. São Paulo: Editora 34, 2011 b.

DELEUZE, Gilles. Gaguejou... In: Crítica e clínica. Tradução de Peter Pál Pelbart. São Paulo: Editora 34, 2011c.

DELEUZE, Gilles; GUATTARI, Félix. L'anti-Oepide - capitalisme et schizophrénie 1. Paris: Les Éditions de Minuit, 2018.

DERRIDA, Jacques; BERGSTEIN, Norma. Enlouquecer o subjétil. Tradução de Geraldo Gerson de Souza. São Paulo: Ateliê Editorial Ltda, 1998.

GROSSMAN, Évelyne. Le corps-xylophène d'Antonin Artaud (Préface). In: Pour en finir avec le jugement de dieu. Paris: Éditions Gallimard, 2003.

GROSSMAN, Évelyne. La défiguration - Artaud - Beckett - Michaux. Paris: Les Éditions de Minuit, 2004.

LAPOUJADE, David. Las existencias menores. Traducción de Pablo Ires. Buenos Aires: Ed. Cactus, 2018.

LYOTARD, Jean-François. Lectures d'enfance. Paris: Galilée, 1991.

Artigo submetido em: 04 ago. 2021

Aceito para publicação em: 13 out. 2021

DOI: https://dx.doi.org/10.22456/2238-8915.117435 